\title{
Optimal generation scheduling strategy for profit maximization of genco in deregulated power system
}

\author{
${ }^{1}$ Mr. K. Asokan, ${ }^{2}$ Dr. R. Ashokkumar \\ ${ }^{1,2}$ (Department of Electrical Engineering, Annamalai University, Annamalai nagar, Tamil nadu, India)
}

\begin{abstract}
A GA based optimal generation scheduling strategy is developed to solve the profit maximization problem for GENCO in the day ahead market. It is a multi objective formulation that includes the forecasted demand, forecasted market clearing price, startup cost and profit functions, besides the generating limits and demand constraints. The proposed GA approach is investigated on three unit and ten unit test systems and numerical results are tabulated. This results shows that this method effectively maximize the GENCO's profit and compared with that of a traditional methods.
\end{abstract}

Keywords: Electricity power market, Generation scheduling, Genetic algorithm, spinning reserve, GENC Profit.

$\begin{array}{ll}\text { NOMENCLATURE } \\ P F & \text { Total profit of GENCO's } \\ R V & \text { Total revenue of GENCO's } \\ T C & \text { Total generation cost of GENCO's } \\ P_{\mathrm{it}} & \text { Real power output of the } i^{\text {th }} \text { generator at an hour of } \mathrm{t} \\ P_{\mathrm{i}}(\mathrm{t}) & \text { Real power output of } i^{t h} \text { Generator } \\ P_{D}(t) & \text { Forecasted system demand during hour } \mathrm{t} \\ \mathrm{P}_{i}^{\text {max }}(t) & \text { Maximum generation limit of } i^{\text {th }} \text { generator during hour of } \mathrm{t} \\ \mathrm{P}_{i}^{\text {min }}(t) & \text { Minimum generation limit of } i^{\text {th }} \text { generator during hour of } \mathrm{t} \\ S P_{t} & \text { Forecasted market price at hour of } \mathrm{t} \\ T & \text { Number of time Periods considered } \\ N & \text { No of generating units } \\ a_{i}, b_{i}, c_{i} & \text { Cost co-efficient of the } i^{\text {th }} \text { generator } \\ G E N C O & \text { Generation Company } \\ T R A N S C O & \text { Transmission Company } \\ D I S C O & \text { Distribution Company } \\ I S O & \text { Independent system operator } \\ P X & \text { Power exchange } \\ N G C & \text { National Grid Company } \\ R_{i}(t) & \text { Reserve } i^{t h} \text { generating unit during hour of t } \\ \mathrm{SR}(t) & \text { Spinning reserve during hour of t } \\ \mathrm{PM} & \text { Proposed Method } \\ U_{i t} & \text { Unit status }\end{array}$

\section{INTRODUCTION}

The restructuring of electricity has changed the role of traditional entities in a vertically integrated utility and created new entities that can function independently. The new entities are GENCO, TRANSO, and DISCO. The main objective of the introduction of competition in the electricity supply industry is to increase efficiency in the production and distribution of electricity, providing better choice to market participants, while maintaining the security and reliability of supply. The fundamental idea behind this is the commercial separation of electric energy as a product from its transmission as a service, the ultimate goal being to protect the interest of the consumers [1]. At the same time, the utilities must also be kept in business by ensuring sufficient revenue recovery that would meet their targeted profit levels.

In the paper [2] and [3] the deregulated environment, generation, transmission and retail services are unbundled also provided by a distinct entity. The main entities involved in the provision of transmission services are Independent System Operator (ISO) and Transmission Companies (TRANSCOs). Generating Companies (GENCOs) and Distribution Companies (DISCOS) are the main users of transmission services. Most of the restructured models have wholesale power pools or Power Exchanges (PX) and Scheduling Coordinators (SCs). The electricity market [4] can trade through a centralized market, bilateral contracts, or both. Not only should a competitive electricity market be efficient, meaning that it either operates at or very close to its optimal 
operating point, it should also be price - driven, therefore requiring the existence of a fair, transparent and open price-setting mechanism. The factors that favor market efficiency include the number of participants and the information exchange mechanisms - in an efficient market, all participants have sufficient information about the prices, supply and demand.

The review is to promote competition by facilitating entry and exit from the electricity market, thus increasing its efficiency and providing greater choice to market participants, while maintaining the operation of a secure and reliable system. Among the principals of the new arrangements are to abandon the current centralized [5] scheduling and pricing mechanisms, to minimize central administration and increase participation from the demand side, and to give market participants the ability to freely negotiate their sales and purchases, based on the level of risk they are able and willing to accept. Trades could be arranged a few years in advance via the use of forwards or futures contracts or through short-term screen -based power exchanges. Participation in the market would be entirely voluntary, with terms negotiated between the parties involved. The settling of trades would be left to the market participants, while the balance of supply and demand would be achieved through a separate balancing mechanism.

A host of solution techniques such as integer programming, dynamic programming, lagrangian relaxation and simulation techniques are available to solve optimal generation scheduling problem [6-8]. Researchers also presented a review on deterministic, meta-heuristic and hybrid approaches of generation scheduling in both regulated and deregulated power markets. All the above methods have their own advantages and also disadvantages. [8-14]

The objective of this paper is to develop a genetic algorithm based optimal generation scheduling and the constrains handled are power balance, unit capacity limits. The method is simple and execution time is less when compared with other conventional methods. The proposed method is applied on two test system to illustrate its performance and the results are presented.

\section{PROBLEM FORMULATION}

as

The proposed GA is formulated as an optimization problem that maximizes [14] the GENCO's profit

$$
\text { Maximize } P F=R V-T C
$$

$$
\operatorname{Max} P F_{i t}=\sum_{i=1}^{N} \sum_{t=1}^{T} P_{i t} S P_{t} \cdot U_{i t}-\left(C_{i t}\left(P_{i t}\right)+S T_{i t}\right) U_{i t}
$$

where, $i=1,2 \ldots N \& \quad t=1,2 \ldots . T$

The equation (2.2) represents the GENCO's profit, which is the difference between the revenue (based on the forecasted market price of electricity) and the cost of power generation. The total cost $\mathrm{F}_{\mathrm{i}}\left(\mathrm{P}_{\mathrm{i}}(\mathrm{t})\right)$ includes the start-up, shut-down and operating costs of a unit. However, we could also present the startup cost as a function of cost (dollars) instead of fuel.

$C_{i t}\left(P_{i t}\right)=a_{i} P_{i}^{2}+b_{i} P_{i}+c_{i} \quad \$ / h$

$a_{i}, b_{i}, c_{i}$ are the $i^{\text {th }}$ GENCO's cost parameters which are included in the GENCO's offer parameters. The objective is to maximize profit while satisfying the constraints on the demand, Generating unit limits and unit output and ramp up or down time of unit.

\section{Subject to constraints...}

\section{(i) GENCO's demand constraint}

$$
\sum_{t=1}^{N} P_{i}(t) U_{i t} \leq P_{D}(t)
$$

This inequality constraint shows that the total power generated by a GENCO should be less than or equal to the forecasted system demand. It is to be emphasized that a GENCO is not responsible for supplying the system demand which is the ISO's responsibility. A GENCO will supply a portion of the demand that maximizes its profit which will be determined by the optimization problem.

\section{(ii) Generating Unit Limits}

$$
P_{i}^{\min }(t) \leq P i(t) \leq P_{i}^{\max }(t)
$$

The power generated for each unit must be within a certain range represented by its minimum power output $\left(P_{i}^{\text {min }}\right)$ and its capacity $\left(P_{i}^{\max }\right)$.

\section{(iii) Spinning reserve}

To ensure that the power system can recover from an unplanned contingency, a pre-specified amount of operating reserves for the system needs to be maintained. This system operating requirement is then converted into corresponding individual contributions from each of the generators supplying energy to a given 
power system. The relationship of the MW output of a generating unit to its operating-reserve obligation can be represented in the following manner.

$$
\sum_{i=1}^{N} R_{i}(t) U_{i t} \leq S R(t)
$$

\section{Genetic Algorithm}

\section{SOLUTION METHODOLOGY}

Genetic Algorithm (GA) is an optimization technique based on the Natural evolution process. They are a very general algorithm [15] and so will work well in any search space. A first step of GA is the creation of initial population and the size is determined by experimentation. The second step is that of Evaluation wherein the variables are read and decoded and function values are evaluated. The third step is Reproduction where in the weaker members are replaced by stronger based on fitness values. Crossover is performed in the fourth step to produce offspring's. Mutation is performed in the fifth step so that parent selection and cross over operations do not lead to identical individuals.

In this study, the value of the objective functions (profit) is used to designate the fitness function. To evaluate the total profit of a GA string the optimal value of loading for each committed GENCO needs to be determined by solving different (one at each hour) power calculation sub-problems whereby we try to maximize the profit for the particular string. This is based on the feasible and operating range of the control variables. The first population is randomly initialized. Here population size is 20; initially many individual solutions are randomly generated to form an initial population. The population size depends on the nature of the problem, but typically contains several hundreds or thousands of possible solutions. Traditionally, the population is generated randomly, covering the entire range of possible solutions (the search space). Occasionally, the solutions may be "seeded" in areas where optimal solutions are likely to be found. Reproduction is the process in which individuals are copied according to their profit function.

In simple GA, strings are selected in the mating pool by Simple Roulette wheel selection. The following two schemes are applied for the selection of parents so that the string with large values of fitness is copied more into the mating pool. Besides standard single point crossover, another crossover operation has been used in this work. According to this scheme; one randomly chosen GENCO in one population is exchanged with the status of same unit in other population. Crossover operator creates new chromosomes from randomly selected chromosomes from mating pool. The crossover operator is carried out according to a rate of crossover. In this study crossover rate is defined as 0.8 and the type of crossover is scattered. Our approach is as follow: Two chromosomes are selected from mating pool as parents, randomly. A number is selected from interval $(0$, 1) randomly and uniformly. If random number is less than crossover rate then crossover operator create two new chromosomes as child from parents, else parents will be copied in child chromosomes cell by cell. After selection and crossover, you now have a new population full of individuals. Some are directly copied, and others are produced by crossover. In order to ensure that the individuals are not all exactly the same, you allow for a small chance of mutation. You loop through all the alleles of all the individuals, and if that allele is selected for mutation, you can either change it by a small amount or replace it with a new value. The probability of mutation is usually between 1 and 2 tenths of a percent. A visual for mutation is shown below. As you can easily see, mutation is fairly simple. You just change the selected alleles based on what you feel is necessary and move on. Mutation is, however, vital to ensuring genetic diversity within the population. In mutation operator is used to form the new strings. So it must return to first step for fitness calculation. Mutation rate is considered as 0.2 and the type is Gaussian.

\section{Simulation AND RESUlTS}

The proposed methodology is tested to evaluate its accuracy on 3 unit 12 hour system and 10 unit 24 hour system [9] using MATLAB. The unit data for 3 unit 12 hour system, 10 unit 24 hour system and forecasted demand and spot price for these system are given in tables I, II, V and VI. Initial status in these tables indicates the status of generator of concerned unit before starting the scheduling hour. GA parameters setting are shown in table III.

Case 1; In this case, three generating units system is considered. The results obtained by the proposed method are compared with the results of conventional method. The solution of the PM for the 3 unit 12 hour system including the Revenue, Total generation cost, and PM profit are given in the table IV. The graphical representation of fuel costs, revenue costs and profits of three unit system are shown fig - 2 


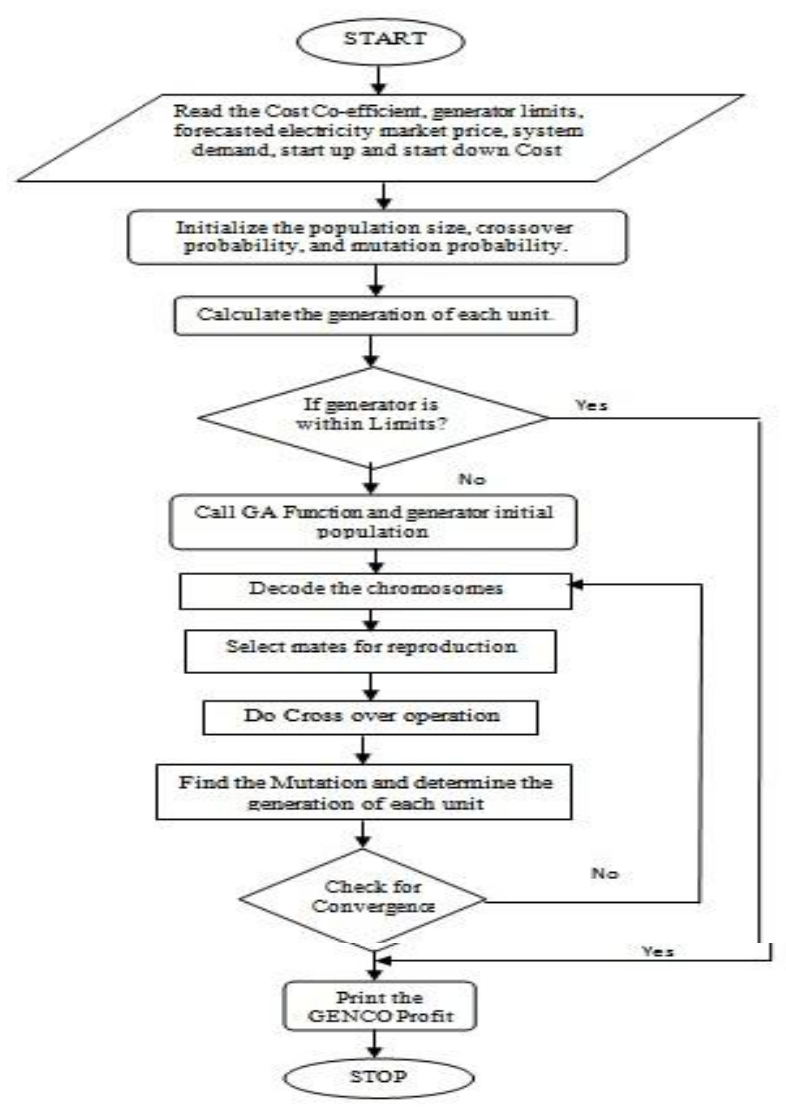

Fig-1 Flow chart of the proposed method

V.

UNIT DATA FOR THREE UNIT SYSTEM

TABLE-I

\begin{tabular}{|c|c|c|c|}
\hline & Unit 1 & Unit 2 & Unit 3 \\
\hline $\mathrm{P}_{\max }(\mathrm{MW})$ & 600 & 400 & 200 \\
\hline $\mathrm{P}_{\min }(\mathrm{MW})$ & 100 & 100 & 50 \\
\hline $\mathrm{a}(\$ / \mathrm{h})$ & 500 & 300 & 100 \\
\hline $\mathrm{b}(\$ / \mathrm{MWh})$ & 10 & 8 & 6 \\
\hline $\mathrm{c}\left(\$ \mathrm{MW}^{2} \mathrm{~h}\right)$ & 0.002 & 0.0025 & 0.005 \\
\hline Min Up time $(\mathrm{h})$ & 3 & 3 & 3 \\
\hline Min down time $(\mathrm{h})$ & 3 & 3 & 3 \\
\hline Startup cost $(\$)$ & 450 & 400 & 300 \\
\hline Initial status $(\mathrm{h})$ & -3 & 3 & 3 \\
\hline
\end{tabular}

FORECASTED DEMAND AND SPOT PRICE FOR THREE UNIT 12 HOUR SYSTEM

TABLE-II

\begin{tabular}{|c|c|c|c|}
\hline $\begin{array}{c}\text { Hour } \\
(\mathrm{h})\end{array}$ & $\begin{array}{c}\text { Forcased } \\
\text { demand } \\
(\mathrm{MV})\end{array}$ & $\begin{array}{c}\text { Forecasted } \\
\text { Market Price } \\
(\$ / \mathrm{MWh})\end{array}$ & $\begin{array}{c}\text { Forecasted } \\
\text { Reserve } \\
(\mathrm{MW})\end{array}$ \\
\hline 1 & 170 & 10.55 & 20 \\
\hline 2 & 250 & 10.35 & 25 \\
\hline 3 & 400 & 9.00 & 40 \\
\hline 4 & 520 & 9.45 & 55 \\
\hline 5 & 700 & 10.00 & 70 \\
\hline 6 & 1050 & 11.25 & 95 \\
\hline 7 & 1100 & 11.30 & 100 \\
\hline 8 & 800 & 10.65 & 80 \\
\hline 9 & 650 & 10.35 & 65 \\
\hline
\end{tabular}




\begin{tabular}{|l|l|l|l|}
\hline 10 & 330 & 11.20 & 35 \\
\hline 11 & 400 & 10.75 & 40 \\
\hline 12 & 550 & 10.60 & 55 \\
\hline
\end{tabular}

GA PARAMETERS SETTING

TABLE-III

\begin{tabular}{|l|c|}
\hline Population size & 20 \\
\hline Crossover Probability & 0.80 \\
\hline Mutation probability & 0.2 \\
\hline Elitism & 2 \\
\hline No. of Generations & 500 \\
\hline
\end{tabular}

SIMULATION RESULTS FOR THREE UNIT 12 HOUR SYSTEM

TABLE- IV

\begin{tabular}{|c|c|c|c|c|c|}
\hline \multirow[t]{2}{*}{$\begin{array}{l}\text { Hour } \\
\text { (h) }\end{array}$} & \multirow{2}{*}{$\begin{array}{c}\text { Power } \\
\text { Demand } \\
(\mathrm{MW})\end{array}$} & \multirow[t]{2}{*}{$\begin{array}{l}\text { Revenue } \\
\text { (\$/MWh) }\end{array}$} & \multirow{2}{*}{$\begin{array}{c}\text { Total } \\
\text { generation } \\
\text { cost } \\
(\$ / \mathrm{h})\end{array}$} & \multicolumn{2}{|c|}{$\begin{array}{c}\text { Profit } \\
(\$)\end{array}$} \\
\hline & & & & $\begin{array}{l}\text { Conventiona } \\
1 \text { method }\end{array}$ & $\begin{array}{l}\text { Proposed } \\
\text { method }\end{array}$ \\
\hline 1 & 170 & 2635.55 & 2064.50 & 126.5 & 540.00 \\
\hline 2 & 250 & 3225.00 & 2706.25 & 352.9 & 520.00 \\
\hline 3 & 400 & 4945.55 & 4145.50 & 103.6 & 320.00 \\
\hline 4 & 720 & 5558.65 & 5257.10 & 303.1 & 394.00 \\
\hline 5 & 700 & 7441.12 & 7000.00 & -363.2 & 206.00 \\
\hline 6 & 1050 & 11812.50 & 10805.00 & 1017.8 & 1352.00 \\
\hline 7 & 1100 & 12430.50 & 11400.00 & 1040.9 & 1385.00 \\
\hline 8 & 800 & 8506.20 & 7987.20 & 548.4 & 986.00 \\
\hline 9 & 650 & 7082.12 & 6429.90 & 308.1 & 812.00 \\
\hline 10 & 330 & 3696.00 & 3182.25 & 91.1 & 815.00 \\
\hline 11 & 400 & 4303.64 & 3849.40 & 159.7 & 802.00 \\
\hline 12 & 550 & 5832.48 & 5035.50 & 359.9 & 925.00 \\
\hline & & & Total profit & 4048.80 & 9057.00 \\
\hline
\end{tabular}

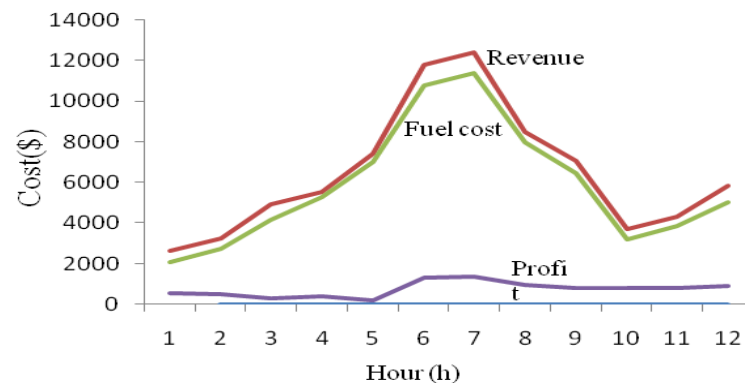

Fig -2 Revenue, Fuel cost and profit for the Three unit 12 hour system

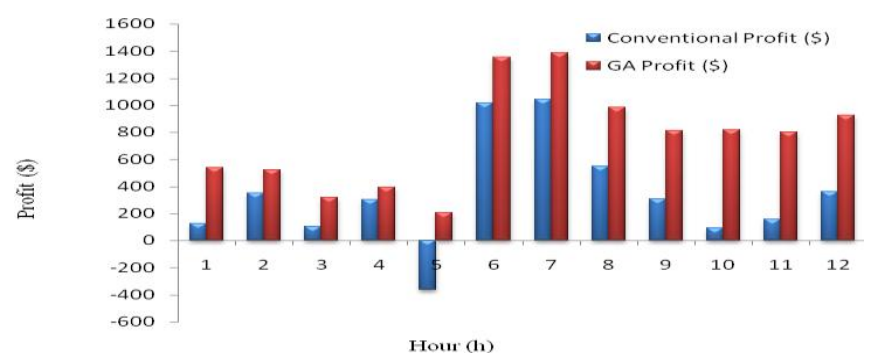

Fig -3 Comparison of profits with proposed and conventional method for three unit 12 hour system 
Optimal generation scheduling strategy for profit maximization of genco in deregulated power system

Case 2; In this case, 10 units, 24 hour system is considered. The results obtained by the proposed method are compared with the results of conventional method. The solution of the PM for the 10 units 24 hour system including the Revenue, Total generation cost, and PM profit are given in the table VII. The graphical representation of fuel costs, revenue costs and profits of ten unit 24 hour system are shown fig-4.

Unit Data For Ten Unit System

Table-V

\begin{tabular}{|c|c|c|c|c|c|}
\hline & Unit 1 & Unit 2 & Unit 3 & Unit 4 & Unit 5 \\
\hline $\mathrm{P}_{\max }$ & 455 & 455 & 130 & 130 & 162 \\
\hline $\mathrm{P}_{\min }$ & 150 & 150 & 20 & 20 & 25 \\
\hline $\mathrm{a}$ & 0.00048 & 0.00031 & 0.20200 & 0.00211 & 0.00398 \\
\hline $\mathrm{b}$ & 16.19 & 17.26 & 16.60 & 16.50 & 19.70 \\
\hline $\mathrm{c}$ & 1000 & 970 & 700 & 680 & 450 \\
\hline Min up & 8 & 8 & 5 & 5 & 6 \\
\hline Min down & 8 & 8 & 5 & 5 & 6 \\
\hline $\mathrm{ST}$ & 4500 & 5000 & 550 & 560 & 900 \\
\hline Initial & 8 & 8 & -5 & -5 & -6 \\
\hline & Unit 6 & Unit 7 & Unit 8 & Unit 9 & Unit 10 \\
\hline $\mathrm{P}_{\max }$ & 80 & 85 & 55 & 55 & 55 \\
\hline $\mathrm{P}_{\min }$ & 20 & 25 & 10 & 10 & 10 \\
\hline $\mathrm{A}$ & 0.20712 & 0.00079 & 0.20413 & 0.00222 & 0.00173 \\
\hline $\mathrm{B}$ & 22.26 & 27.74 & 25.92 & 27.27 & 27.79 \\
\hline $\mathrm{C}$ & 370 & 480 & 660 & 665 & 670 \\
\hline Min up & 3 & 3 & 1 & 1 & 1 \\
\hline Min down & 3 & 3 & 1 & 1 & 1 \\
\hline $\mathrm{ST}$ & 170 & 260 & 30 & 30 & 30 \\
\hline Initial & -3 & -3 & -1 & -1 & -1 \\
\hline & & & & & \\
\hline
\end{tabular}

Forecasted Demand And Spot Price For Ten Unit 24 Hour System Table-Vi

\begin{tabular}{|c|c|c|c|}
\hline $\begin{array}{l}\text { Hour } \\
\text { (h) }\end{array}$ & $\begin{array}{c}\text { Forecasted } \\
\text { Demand } \\
(\mathrm{MW})\end{array}$ & $\begin{array}{c}\text { Forecasted } \\
\text { Reserve } \\
(\mathrm{MW})\end{array}$ & $\begin{array}{c}\text { Forecasted } \\
\text { Market price } \\
(\$ / \mathrm{MWh})\end{array}$ \\
\hline 1 & 700 & 70 & 22.15 \\
\hline 2 & 750 & 75 & 22.00 \\
\hline 3 & 850 & 85 & 23.10 \\
\hline 4 & 950 & 95 & 23.65 \\
\hline 5 & 1000 & 100 & 22.25 \\
\hline 6 & 1100 & 110 & 22.95 \\
\hline 7 & 1150 & 115 & 22.50 \\
\hline 8 & 1200 & 120 & 22.15 \\
\hline 9 & 1300 & 130 & 22.80 \\
\hline 10 & 1400 & 140 & 29.35 \\
\hline 11 & 1450 & 145 & 30.15 \\
\hline 12 & 1500 & 150 & 31.65 \\
\hline 13 & 1400 & 140 & 24.60 \\
\hline 14 & 1300 & 130 & 24.50 \\
\hline 15 & 1200 & 120 & 22.50 \\
\hline 16 & 1050 & 105 & 22.30 \\
\hline 17 & 1000 & 100 & 22.25 \\
\hline 18 & 1100 & 110 & 22.05 \\
\hline 19 & 1200 & 120 & 22.20 \\
\hline 20 & 1400 & 140 & 22.65 \\
\hline 21 & 1300 & 130 & 23.10 \\
\hline 22 & 1100 & 110 & 22.95 \\
\hline 23 & 900 & 90 & 22.75 \\
\hline 24 & 800 & 80 & 22.55 \\
\hline
\end{tabular}


Optimal generation scheduling strategy for profit maximization of genco in deregulated power system SIMULATION RESULTS FOR TEN UNIT 24 HOUR SYSTEM

TABLE - VII

\begin{tabular}{|c|c|c|c|c|c|}
\hline \multirow[t]{2}{*}{$\begin{array}{l}\text { Hour } \\
\text { (h) }\end{array}$} & \multirow{2}{*}{$\begin{array}{c}\text { Power } \\
\text { Demand } \\
(\mathrm{MW})\end{array}$} & \multirow[t]{2}{*}{$\begin{array}{l}\text { Revenue } \\
\text { (\$/MWh) }\end{array}$} & \multirow[t]{2}{*}{$\begin{array}{l}\text { Fuel cost } \\
(\$ / h)\end{array}$} & \multicolumn{2}{|c|}{$\begin{array}{l}\text { Profit } \\
(\$)\end{array}$} \\
\hline & & & & $\begin{array}{l}\text { Conventional } \\
\text { method }\end{array}$ & Proposed method \\
\hline 1 & 700 & 15520.505 & 13695 & 1822 & 1825.50 \\
\hline 2 & 750 & 16516.50 & 14568 & 1946 & 1948.50 \\
\hline 3 & 850 & 19654.63 & 16317 & 3333 & 3337.63 \\
\hline 4 & 950 & 22489.96 & 18617 & 1647 & 3872.97 \\
\hline 5 & 1000 & 22272.25 & 19629 & 629 & 2643.25 \\
\hline 6 & 1100 & 25270.24 & 22261 & 697 & 1150.24 \\
\hline 7 & 1150 & 25900.87 & 23098 & 3120 & 2802.87 \\
\hline 8 & 1200 & 26606.58 & 23946 & -34 & 2660.58 \\
\hline 9 & 1300 & 29669.64 & 26273 & 3456 & 2396.64 \\
\hline 10 & 1400 & 41131.09 & 28791 & 11982 & 12340.09 \\
\hline 11 & 1450 & 43761.21 & 30624 & 11813 & 13137.21 \\
\hline 12 & 1500 & 47522.47 & 32668 & 13658 & 15954.47 \\
\hline 13 & 1400 & 34474.44 & 28801 & 5672 & 5693.44 \\
\hline 14 & 1300 & 31881.85 & 26328 & 5666 & 5753.85 \\
\hline 15 & 1200 & 27027.00 & 23946 & 2175 & 3181.00 \\
\hline 16 & 1050 & 23438.41 & 20661 & 2410 & 2577.41 \\
\hline 17 & 1000 & 22272.25 & 16629 & -3334 & 873.25 \\
\hline 18 & 1100 & 24279.25 & 22261 & 2376 & 2418.25 \\
\hline 19 & 1200 & 26666.64 & 23964 & 2868 & 2902.64 \\
\hline 20 & 1400 & 31741.71 & 28801 & -5375 & 3240.71 \\
\hline 21 & 1300 & 30060.03 & 26328 & -241 & 3932.03 \\
\hline 22 & 1100 & 25270.24 & 22261 & 2897 & 3009.24 \\
\hline 23 & 900 & 20495.47 & 17194 & 3297 & 3301.47 \\
\hline \multirow[t]{2}{*}{24} & 800 & 18058.04 & 15441 & 2613 & 2717.04 \\
\hline & & & Total Profit & 75093 & 104670.33 \\
\hline
\end{tabular}

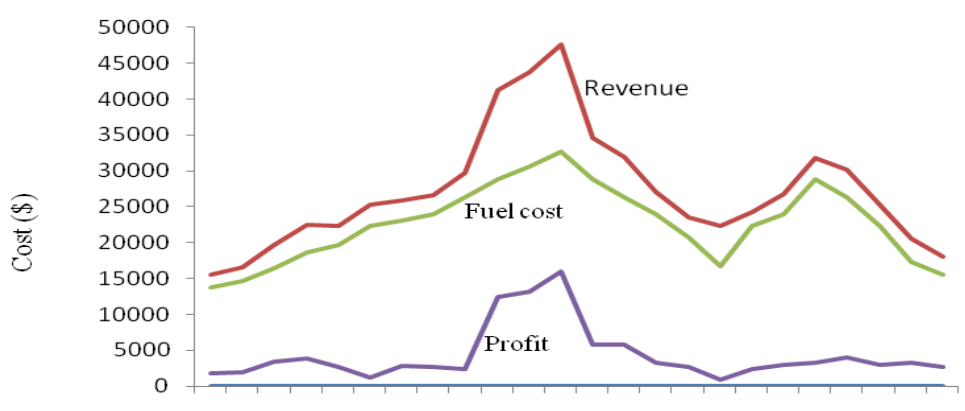

$\begin{array}{lllllllllll}1 & 2 & 3 & 4 & 5 & 6 & 7 & 8 & 9 & 101112131415161718192021222324\end{array}$

Hour (h)

Fig-4 Revenue, Fuel cost and profit for the Ten unit 24 hour system

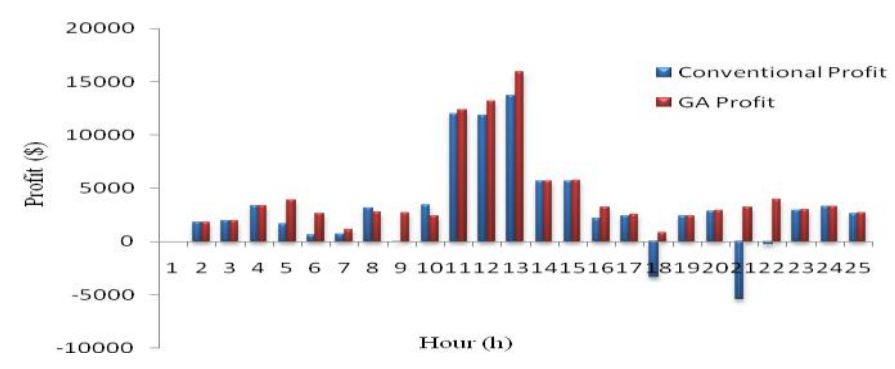

Fig-5 Comparison of profits with proposed and conventional method for ten unit 24 hour system 


\section{Conclusions}

The genetic algorithm has been applied to solve the Gencos profit maximization problem by considering the constraints such as generating limits and Gencos demand in the day ahead market. A multi objective profit maximization problem has been proposed based on some assumptions such as forecasted load and forecasted Market Clearing Price (MCP). Two different size systems are used to demonstrate the effectiveness of the proposed GA approach for GENCOs. The simulation results have been compared with the results obtained from conventional method to highlight the superiority of the proposed approach.

\section{Acknowledgements}

The authors gratefully acknowledge the authorities of Annamalai University for the facilities offered to carry out this work.

\section{REFERENCES}

[1.] Hunt. S, and Shutingworth. G "Competition and choice in Electricity”, (john Wiley \& Sons

[2.] Ltd., West Sussex , England, 1996), pp. 1-7.

[3.] H.Y. Yamin, J.D. Finney, W. Rutz, H. Holly "Gencos portfolio management using "strategist" in deregulated power markets" Raleigh. NC 276060-7803-7107-0/01/\$10.00 02001 IEEE.

OFER-Office of Electricity Regulation "Reviewof ElectricityTrading arrangements Proposals", July 1998.

[4.] Mohammad Shahidehpour, H.Yamin, and Zuyili, "Market Operations in Electric Power Systems: Forecasting, Scheduling and Risk Management". New York: Wiley, Book- 2002.

[5.] G.B. Shrestha, and Qiao Songbo "Generation Scheduling for a Price Taker GENCO in Competitive Power Markets" 978-1-42443811-2/09/\$25.00 @2009 IEEE.

[6.] Mohammad Shahidehpour and Hatim yamin,salem, AI-agtash, "Security Constrained Optimal Generation Scheduling for GENCOs” IEEE Transactions on power systems, vol. 19, August 2004.

[7.] H.Y. Yamin, S.M. Shahidehpour“Self-scheduling and energy bidding in competitive electricity markets" Electric Power Systems Research, Volume 71, Issue 3, Pages 203-209, November 2004.

[8.] Lei Wu, Mohammad Shahidehpour, Fellow, and Zuyi Li “GENCO's Risk-Constrained Hydrothermal Scheduling” IEEE transactions on power systems, vol. 23, No. 4, November 2008.

[9.] Pathom Attaviriyanupap, Hiroyuki Kita, Eiichi Tanaka, and Jun Hasegawa “A Hybrid LR-EP for Solving New Profit-Based UC Problem Under Competitive Environment” IEEE Transactions on power systems, vol. 18, No. 1, February 2003.

[10.] Azadeh, S.F.Ghadrei, B.Pourvalikhan Nokhandan "GENCO Behavior Model and Simulation in Electricity Market by FCMapproach"IEEE Conference Publications, Page(s): 72 - 79, March 2009.

[11.] K. Chandram, N. Subrahmanyam, M. Sydulu "New approach with Muller method for Profit Based Unit Commitment" IEEE Conference Publications, Page(s): 1 - 8 , July 2008.

[12.] Maria Dicorato, Giuseppe Forte, Michele Trovato, and Ettore Caruso "Risk-Constrained Profit Maximization in Day-Ahead Electricity Market” IEEE Transactions on power systems, vol. 24, No. 3, August 2009.

[13.] T. Ghose, M. Gopi Kishore, and P. Sukumar "Solution of Profit Based Unit Commitment considering Market Equilibrium condition" IEEE Conference Publications , June 2006.

[14.] José M. Arroyo, and Antonio J. Conejos, Fellow "Modeling of Start-Up and Shut-Down Power Trajectories of Thermal Units" IEEE Transactions on power systems, vol. 19, No. 3, August 2004.

[15.] Richter Jr. CW and Sheble GB. "Genetic algorithm evolution of utility bidding strategies for the competitive market place". IEEE Trans Power System, Vol 13, no 1, Page(s): 256 - 26, 1998. 